\title{
The role of recurrent disturbances for ecosystem multifunctionality
}

\section{Villnäs, Anna}

2013

Villnäs , A , Norkko , J , Hietanen , S , Josefson , A , Lukkari , K \& Norkko , A 2013 , ' The role of recurrent disturbances for ecosystem multifunctionality ' , Ecology , vol. 94 , no. 10 , pp. 2275-2287 . https://doi.org/10.1890/12-1716.1

http://hdl.handle.net/10138/233616

https://doi.org/10.1890/12-1716.1

unspecified

publishedVersion

Downloaded from Helda, University of Helsinki institutional repository.

This is an electronic reprint of the original article.

This reprint may differ from the original in pagination and typographic detail.

Please cite the original version. 


\title{
The role of recurrent disturbances for ecosystem multifunctionality
}

\author{
Anna Villnäs, ${ }^{1,2,3,6}$ Joanna Norkko, ${ }^{1}$ Susanna Hietanen, ${ }^{1,4}$ Alf B. Josefson, ${ }^{5}$ KaArina Lukkari, ${ }^{2}$ \\ AND Alf NorkKo ${ }^{1}$ \\ ${ }^{1}$ Tvärminne Zoological Station, University of Helsinki, J.A. Palméns väg 260, FI-10900 Hanko, Finland \\ ${ }^{2}$ Marine Research Centre, Finnish Environment Institute, P.O. Box 140, FI-00251 Helsinki, Finland \\ ${ }^{3}$ Environmental and Marine Biology, Department of Biosciences, Ảbo Akademi University, Artillerigatan 6, FI-20520 Abo, Finland \\ ${ }^{4}$ Aquatic Sciences, Department of Environmental Sciences, University of Helsinki, P.O. Box 65, FI-00014 Helsinki, Finland \\ ${ }^{5}$ Department of Bioscience, Aarhus University, Frederiksborgvej 399, DK-4000, Roskilde, Denmark
}

\begin{abstract}
Ecosystem functioning is threatened by an increasing number of anthropogenic stressors, creating a legacy of disturbance that undermines ecosystem resilience. However, few empirical studies have assessed to what extent an ecosystem can tolerate repeated disturbances and sustain its multiple functions. By inducing increasingly recurring hypoxic disturbances to a sedimentary ecosystem, we show that the majority of individual ecosystem functions experience gradual degradation patterns in response to repetitive pulse disturbances. The degradation in overall ecosystem functioning was, however, evident at an earlier stage than for single ecosystem functions and was induced after a short pulse of hypoxia (i.e., three days), which likely reduced ecosystem resistance to further hypoxic perturbations. The increasing number of repeated pulse disturbances gradually moved the system closer to a press response. In addition to the disturbance regime, the changes in benthic trait composition as well as habitat heterogeneity were important for explaining the variability in overall ecosystem functioning. Our results suggest that disturbance-induced responses across multiple ecosystem functions can serve as a warning signal for losses of the adaptive capacity of an ecosystem, and might at an early stage provide information to managers and policy makers when remediation efforts should be initiated.
\end{abstract}

Key words: field study; habitat heterogeneity; hypoxia; multiple ecosystem functions; recurring disturbances; resilience; resistance.

\section{INTRODUCTION}

Ecosystems provide multiple functions such as elemental cycling, physical structuring, and production, which are of immense value to humanity. As human dominance over ecosystems has grown, anthropogenic disturbances have increased in frequency, extent, and intensity, threatening ecosystem biodiversity and functionality (Vitousek et al. 1997). This has resulted in a critical need to understand ecosystem resilience, i.e., the ability of a system to sustain its domain of stability when facing external disturbances and internal change (Holling 1973, Cumming et al. 2005), which provides an insurance against impairment of ecosystem functions (Thrush et al. 2009). Theoretical studies indicate that the resilience of an ecosystem is affected by its disturbance history, as slowly degrading conditions can make a system increasingly vulnerable to further perturbations (Scheffer et al. 2001, Suding and Hobbs 2009). There is, however, little empirical insight regarding the extent to

Manuscript received 4 October 2012; revised 13 February 2013; accepted 28 March 2013. Corresponding Editor: S. A. Navarrete.

${ }^{6}$ Present address: Tvärminne Zoological Station, J.A. Palméns väg 260, FI-10900 Hanko, Finland.

E-mail: anna.villnas@environment.fi which an ecosystem can tolerate repeated disturbances and still sustain its functionality (Thrush et al. 2009).

Disturbance has been defined as "any relatively discrete event in time that disrupts ecosystem, community, or population structure and changes resources, substrate availability or the physical environment" (White and Pickett 1985). The recurrence of natural disturbances is often limited over time relative to the generation time of the residing biota, and may consist of a few events within or among years (Smith et al. 2009). Natural disturbances have thus often been regarded as "pulse" disturbances, i.e., short-term, delineated disturbances, from which the system can return to its previous equilibrium (Bender et al. 1984). Due to human activities, the frequency (i.e., rate of occurrence) of such disturbances have, however, been observed to increase (Lake 2000, Bengtsson et al. 2003, Smith et al. 2009). When a disturbance becomes continuous and exerts a constant level of stress, it is defined as a "press" disturbance (Bender et al. 1984, Lake 2000), and such a perturbation might change the stability of the system (Ives and Carpenter 2007) and have severe implications for ecosystem functioning (Thrush et al. 2009). However, even small disturbances can lead to dramatic shifts in environmental state (Scheffer et al. 2001, Ives and Carpenter 2007), and the response of an ecosystem may thus not be proportional to the magnitude of distur- 
bance (Glasby and Underwood 1996, Lake 2000, Smith et al. 2009). This emphasizes the need for assessing the consequences of increasingly recurring disturbances for ecosystem resilience and for changes in overall functioning.

Increasing evidence indicates that humans influence ecological resilience by changing the biological capacity of ecosystems to withstand disturbances (Suding and Hobbs 2009, Thrush et al. 2009). A major part of recent research considering disturbance-induced changes in ecosystem functions has focused on the consequences of biodiversity loss. For example, studies have found negative effects of biodiversity loss on ecosystem functions like productivity and decomposition (Hooper et al. 2012), and in marine soft-sediment environments, species extinctions are expected to particularly reduce bioturbation, an important macroinvertebrate-mediated process (Lohrer et al. 2004, Solan et al. 2004). The impact of species on ecosystem functions depends in part on what functional traits they express (Needham et al. 2011, Cardinale et al. 2012). A trait is considered to be a proxy of an organism's performance, describing the morphological, physiological, or phenological characteristics of an individual species (Violle et al. 2007), but it also incorporates the interaction between a species and its environment (cf. Bremner et al. 2003). Consequently, the extent to which a disturbance affects ecosystem functioning depends greatly on the sequence of species lost and which biological traits become impaired (Cardinale et al. 2012). It has thus been emphasized that biodiversity, together with other parameters determining the performance of biotic communities (e.g., functional identity and dominance), is important for sustaining ecosystem functions (Hooper et al. 2005, Hillebrand and Matthiessen 2009). However, biodiversity is not always the only, or even the primary driver of ecosystem functioning (Maestre et al. 2012).

Ecosystems are inherently complex, with functions resulting from the interplay of behavioral, biological, chemical, and physical interactions over a range of spatial and temporal scales (Michener et al. 2001). For example, environmental heterogeneity of habitats has been shown to affect ecosystem processes both directly and through interactions with the biota (Dyson et al. 2007, Tylianakis et al. 2008). Disturbances, whether natural or human-induced, are likely to affect several of the factors and/or interactions that determine a function, often in a nonrandom manner. In a large data synthesis, Hooper et al. (2012) estimated that the direct effects of environmental stressors (e.g., climate warming and ocean acidification) could be of comparable magnitude to the effects of species loss for ecosystem functions such as productivity and decomposition. Still, few studies evaluating changes in ecosystem functioning have considered the consequences of realistic disturbance scenarios in natural complex environments (Naeem et al. 2012). There is thus a need to evaluate the effects of diversity loss together with concurrent structural, physical, and/or chemical environmental change (Hooper et al. 2012). Merely focusing on single ecosystem functions might, however, underestimate the consequences of disturbance-induced changes in biodiversity, as ecosystem multifunctionality is likely to be more susceptible to species loss (Hector and Bagchi 2007, Gamfeldt et al. 2008) and disturbances. Furthermore, the indirect relationships and feedback loops between different functions might be of importance for the resilience of ecosystems subjected to disturbance (Thrush et al. 2012). This emphasizes the importance of accounting for multiple ecosystem functions when examining how natural, complex systems react to different levels of stress.

Disturbances may vary in frequency, extent, and intensity, and the type of disturbance and its specific dimensions is of importance for the effects on ecosystem functioning (Sousa 2001). Hypoxia (i.e., low oxygen levels, $<2 \mathrm{mg} \mathrm{O}_{2} / \mathrm{L}$ ) is a global and highly dynamic stressor to marine ecosystems that has increased in extent and severity due to human-induced eutrophication and global warming (Diaz and Rosenberg 2008). Hypoxia is reported to increase both in coastal areas (Diaz and Rosenberg 2008) and in the open oceans (i.e., expansion of oxygen minimum zones; Levin 2003, Keeling et al. 2010, Ulloa et al. 2012), with severe consequences for marine biogeochemical cycling as well as the biota. Oxygen deficiency is a threat to the ecosystem not only when the hypoxia is permanent, but also when it is intermittent, as hypoxic disturbance can leave a biogeochemical "memory" (i.e., an increased pool of reduced compounds in the sediment), partly resulting from the loss of bioturbating fauna (Hagy et al. 2004, Conley et al. 2007). In coastal zones, the frequency of hypoxic events has increased (Conley et al. 2011), and it has been suggested that frequent hypoxic stress might reduce the resilience of coastal sedimentary ecosystems to future hypoxic disturbance by altering their functioning (Conley et al. 2007, 2009). The consequences of such repeated disturbance for ecosystem functioning will depend on ecosystem resistance to, as well as recovery from, the stress.

Here we report the results of a manipulative field experiment where we investigated the consequences of recurring disturbance events (bottom-water hypoxia) on the multifunctionality of a shallow sedimentary ecosystem in the Baltic Sea. The disturbance had the character of both "pulse" (increasing number of recurring short periods of hypoxia) and "press" (a longer, uninterrupted period of hypoxia) disturbance. We test the overall hypothesis that even short, but repeated, periods of hypoxic disturbance have negative effects on overall ecosystem functioning (i.e., the joint response of many ecosystem functions; Gamfeldt et al. 2008), and that the ecosystem response to increasingly recurring pulses of disturbance will gradually resemble a press response. We chose to focus on one aspect of resilience, i.e., resistance, and measured it by evaluating changes in a range of 
TABLE 1. Selected ecosystem functions and their individual response to increasing occurrence of hypoxic events.

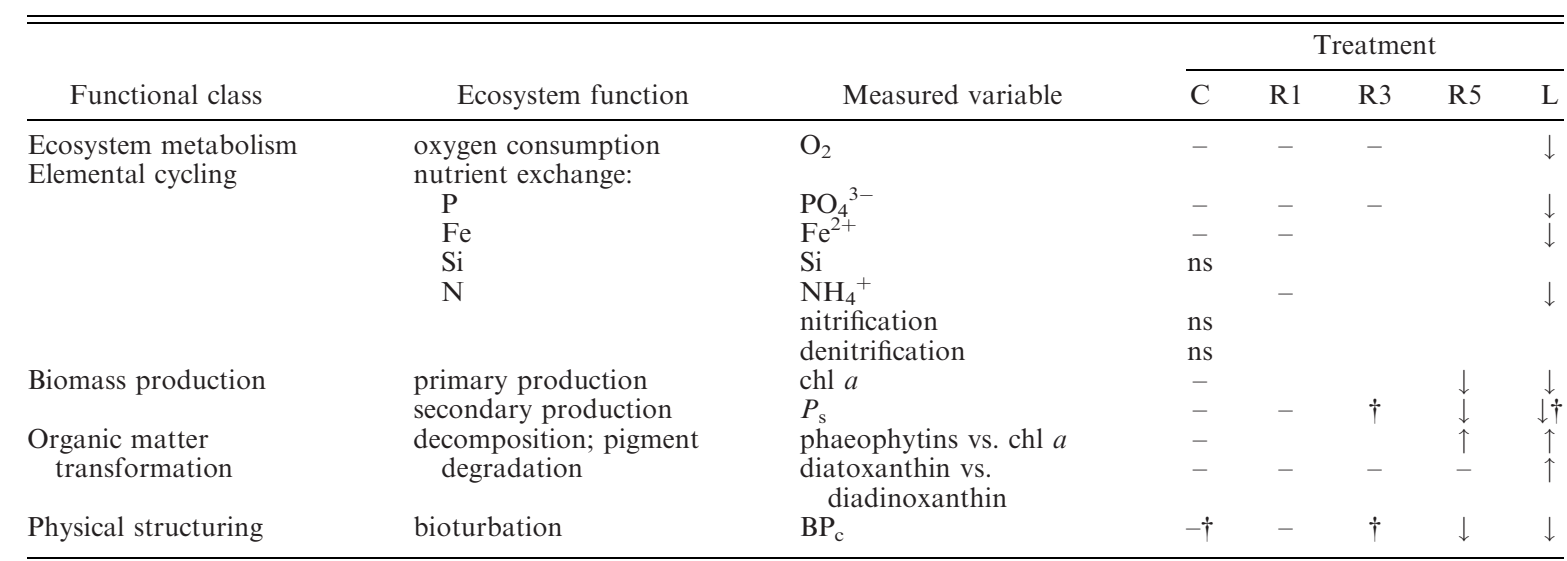

Notes: Differences between treatments were identified with ANCOVA, followed by Tukey's post hoc test $(P<0.05$; Appendix C: Table $\mathrm{C} 1)$. Arrows mark direction of significant increase or decrease in a function, compared to treatments marked with horizontal lines. If Tukey's post hoc test could not separate a treatment from any of the others, the cell is empty. No significant differences for ANCOVA are indicated by "ns" $(P>0.05)$. The treatments were: $\mathrm{C}$, control; R1, repeated 1; R3, repeated 3; R5, repeated 5; L, long, uninterrupted period of hypoxia. $\mathrm{BP}_{\mathrm{c}}$ is the community bioturbation potential.

$\dagger$ Treatments that differ significantly from each other $(P<0.05)$.

ecosystem functions in response to disturbance (cf. Lake 2000, Ives and Carpenter 2007). We specifically explore the following hypotheses: (1) increasing numbers of repeated hypoxic events will result in successively larger changes in ecosystem functioning, illustrating that pulse disturbances increase ecosystem susceptibility to further hypoxic stress; (2) the overall disturbance response in ecosystem multifunctionality will deviate from patterns observed for single ecosystem functions; (3) a large part of the variability in ecosystem multifunctionality can be explained by the number of recurring disturbance events; while (4) a significant amount of change will be due to disturbance-induced changes in the biological trait composition of the macrobenthic community. Changes in trait characteristics such as feeding mode, mobility, size, position in sediment, and reworking mode may have a significant role for ecosystem functioning through their influence on physical habitat structuring, biomass production, and nutrient cycling. We chose a comprehensive set of response measures to represent the multiple ecosystems functions. These functions are important characteristics for aquatic ecosystems (Giller et al. 2004) and depict sediment ecosystem metabolism, elemental cycling, biomass production, organic matter transformation, and physical structuring (Table 1).

\section{Methods \\ Experiment setup}

The experimental site was situated in the Gulf of Finland ( $59^{\circ} 50^{\prime} 24^{\prime \prime}$ N, $23^{\circ} 15^{\prime} 37^{\prime \prime}$ E), northern Baltic Sea. The Baltic Sea is a young brackish-water basin, with low species diversity due to its strong environmental gradients (Villnäs and Norkko 2011). Hypoxia, caused by dense, drifting algal mats or by water column stratification is a severe problem in this sea area. Episodic hypoxia is especially common during late summer (July-October) and might last from days (pulse disturbance) to months (press disturbance; Norkko and Bonsdorff 1996a, Vahteri et al. 2000, Laine et al. 2007, Conley et al. 2011). The short pulses of hypoxic disturbance are known to recur, as weather conditions can change the strength and depth of water column stratification and direct the movement of algal mats, in cases creating repeated occurrences of intermittent hypoxia (Stanley and Nixon 1992, Norkko and Bonsdorff 1996b, Eby et al. 2005, Conley et al. 2007). To investigate the effects of repeated pulses of hypoxic disturbance vs. a longer period of hypoxic stress (press disturbance), we introduced oxygen deficiency to submerged, coastal sediments ( $5 \mathrm{~m}$ depth) by securing $1-\mathrm{m}^{2}$ black plastic sheets to the seafloor (methods as in Norkko et al. 2010, Villnäs et al. 2012). Dark plastic has proved to be an efficient way of inducing standardized levels of hypoxia, as it prevents the exchange of oxygen across the sediment-water interface and the oxygen production by benthic primary producers. Dark conditions are representative of hypoxic conditions introduced beneath drifting algal mats or by water-column stratification beneath the photic zone. Our experiment included five treatments (Appendix A) each replicated four times. The treatments represented undisturbed sediments ( $\mathrm{C}$, control), sediments exposed to a long, uninterrupted period of hypoxia (i.e., 30 days of press disturbance, L, long), as well as sediments exposed to increasing recurrences of short pulses of hypoxia, i.e., repeated 1,3 , and 5 ( $\mathrm{R} 1, \mathrm{R} 3$, and $\mathrm{R} 5$, respectively). Treatment R1 was exposed to one hypoxic pulse, i.e., three days of hypoxia. The intermittent hypoxic disturbance in treatment R3 was induced by repeating the pulse of short hypoxia (i.e., three days) three times for each replicate plot. Between the pulses of hypoxia, oxic conditions were allowed to reestablish by removing 
the plastic for four days. Four days of oxic conditions may partly reestablish biogeochemical processes that depend on molecular diffusion and hydrodynamic forcing (Middelburg and Levin 2009), but this period is not likely to allow for a full recovery of the considered ecosystem functions (Larson and Sundbäck 2008). For treatment R5, there were five pulses of short hypoxic disturbance (each one again lasting three days), in between which oxic conditions were reestablished during four days by removing the plastic. The disturbance was ended simultaneously for the R1, R3, R5, and the L treatment as the plastic was rolled away after the last hypoxic period, and all measurements were done $24 \mathrm{~h}$ after the disturbance ended (in August 2009, water temperatures were between $15^{\circ}$ and $19^{\circ} \mathrm{C}$ ). In order to encompass the natural environmental heterogeneity at the experimental site, the four replicates of each treatment (total $N=20$ ) were placed in a block design along four orthogonal $17 \mathrm{~m}$ long transects, so that each block contained one replicate of each treatment. Each replicate plot was separated by at least $4 \mathrm{~m}$ from the others. The four blocks encompassed a gradient of slightly increasing organic matter $(0.74 \% \pm 0.07 \%$ to $1.99 \% \pm 0.19 \%$, mean $\pm \mathrm{SE}$; for description of sediment analysis and basic sediment properties see Appendix B: Table B1). All manipulations, chamber incubations, and subsequent sampling were done using scuba.

\section{Measures of ecosystem function}

The examined ecosystem functions included aspects of ecosystem metabolism, elemental cycling, biomass production, organic matter transformation, and physical structuring (Table 1). To estimate changes in ecosystem metabolism and elemental cycling, measurements of sediment oxygen consumption and nutrient fluxes were performed with dark benthic chambers, excluding effects of primary production. After the plastic was rolled away, one chamber frame was pressed $6 \mathrm{~cm}$ into the sediment in the center of each plot, resulting in a final water volume of $\sim 6 \mathrm{~L}$. To avoid sampling of initial sediment reactions, flushing of the sediment was allowed for $24 \mathrm{~h}$. Thereafter incubation started by installing dark chamber lids and ended $6.5 \mathrm{~h}$ later. Water samples were taken from the chambers at start and end of the incubation. To correct for water column effects, four 1-L dark LPDE bottles were used for incubation of ambient water during the experiment (for further method description, see Villnäs et al. 2012). Water samples were analyzed for dissolved oxygen concentrations (determined according to the Winkler procedure), while $\mathrm{NH}_{4}{ }^{+}, \mathrm{NO}_{x}\left(\mathrm{NO}_{3}{ }^{-}+\mathrm{NO}_{2}{ }^{-}\right), \mathrm{PO}_{4}{ }^{3-}$, and dissolved $\mathrm{Si}$ (silicate) were measured spectrophotometrically with an autoanalyzer (Lachat QuickChem 8000; Lachat Instruments, Loveland, Colorado, USA). The ICPOES technique was used for measuring $\mathrm{Fe}^{2+}$ (total dissolved $\mathrm{Fe}$ ) concentrations. Changes in phosphorus and nitrogen dynamics were further examined by measuring sediment phosphate $\left(\mathrm{PO}_{4}{ }^{3-}\right)$ sorption and denitrification rates. Phosphate sorption properties of surface sediments $(0-3 \mathrm{~cm} ; 2.0 \mathrm{~cm}$ diameter cores) were studied from the $\mathrm{C}, \mathrm{R} 3$, and $\mathrm{L}$ treatments to clarify the effect of oxygen deficiency on behavior of phosphate at the sediment-water interface (methods modified from Koski-Vähälä and Hartikainen 2001; Appendix B). Denitrification was measured for four replicate samples from each replicate plot, using the isotope pairing technique (Nielsen 1992; Appendix B), and nitrification was calculated as the sum of Dn (coupled nitrificationdenitrification) and the $\mathrm{NO}_{x}$ flux out of the sediment.

The potential for primary biomass production in the sedimentary habitat was estimated by measuring microphytobenthic biomass through chlorophyll $a$ determination, while pigment degradation ratios were used to estimate algal matter decomposition (i.e., by calculating the phaeophytin $a+$ pyrophaeophytin $a$ vs. chl $a$ ratio, and the diatoxanthin vs. diadinoxanthin ratio, $\mathrm{cf}$. Veuger and Van Oevelen 2011). As a brownish, benthic diatom cover was observed on the sediment surface at the experiment site, we assumed that chl a mainly represented microphytobenthic biomass. From every plot a core $(2.0 \mathrm{~cm}$ diameter $)$ was used to obtain sediment samples for the quantitative analyses of pigment concentrations in the uppermost sediment layer $(0-1 \mathrm{~cm})$. Sediments were homogenized and freeze-dried $\left(-70^{\circ} \mathrm{C}\right)$ and the pigment concentrations analyzed on a Shimadzu HPLC according to Josefson et al. (2012).

Secondary biomass production was estimated for the soft-bottom macrobenthic fauna. Benthic fauna was sampled with two replicate cores $(6 \mathrm{~cm}$ diameter, depth $15 \mathrm{~cm}$ ) from each chamber after incubations ended. In addition, all chambers were excavated in order to account for any deeper-burrowing bivalves. Samples were sieved $(0.2 \mathrm{~mm})$, preserved in $70 \%$ ethanol, and stained with rose bengal. The species were identified to the lowest taxonomic level possible. Secondary biomass production was obtained by measuring the total mass of each species (precision $0.1 \mathrm{mg}$ wet mass, including shells of mollusks) and by calculating total somatic production $\left(P_{\mathrm{s}}, \mathrm{kJ} \cdot \mathrm{m}^{-2} \cdot \mathrm{yr}^{-1}\right)$ for each replicate, using T. Brey's (unpublished) multiple regression model. Species-specific biomass data were converted to energy values using published conversion factors (e.g., Lappalainen and Kangas 1975). Using Brey's calculation spread sheet, energy values were converted to production estimates.

Benthic bioturbation, which affects the physical and chemical structure of the sediment, was estimated by classifying the macrobenthic species to traits depicting their size, mobility, sediment-reworking mode, and position. The community bioturbation potential was calculated according to Solan et al. (2004) as $\mathrm{BP}_{c}=\Sigma A_{i}$ $\times B_{i}^{0.5} \times M_{i} \times R_{i}$, where the summation $(\Sigma)$ considers all species in a replicate. $A_{i}$ is the number of individuals of a species per square meter; $B_{i}$ is the average biomass of a species (grams wet mass); $M_{i}$ is species' mobility; and $R_{i}$ is species' reworking mode and position in the sediment. $M_{i}$ and $R_{i}$ are scored on a categorical scale from 1 to 5 , 
based on biological trait information obtained from previously published classifications (e.g., Bonsdorff and Pearson 1999) and taxonomic and morphologic literature sources (e.g., Fish and Fish 1996). Mobility was scored as: 1, grazers on the sediment surface; 2, fixed tube; 3, limited movement in the sediment; 4, slow movement through the sediment; and 5, freely motile. For sediment reworking: 1, epifauna; 2, surficial modifiers, restricted to the uppermost $1-2 \mathrm{~cm}$ of the sediment; 3, head-down/head-up feeders, actively transporting sediment to/from the sediment surface; 4, biodiffusers; and 5, gallery diffusers (Solan et al. 2004, Josefson et al. 2012).

Furthermore, biological trait analysis (BTA) was used to assess changes in the functional structure of the benthic community. Similar biological traits as included in the benthic bioturbation potential (BPc) were selected, but divided into five different traits (i.e., benthic feeding mode, mobility, size, bioturbation mode, and position in sediment). The selected traits were considered important as they are likely to affect the measured ecosystem functions (Solan et al. 2004, Josefson et al. 2012, Villnäs et al. 2012). Each trait was described by several modalities (Villnäs et al. 2012). Species were appointed to each trait according to the fuzzy coding procedure, allowing species affinity to trait modalities to differentiate, summing up to 1 within a trait. A trait matrix was created by correcting each modality for species- and sample-specific abundances (Hewitt et al. 2008).

\section{Statistical analyses}

To identify environmental heterogeneity within the sedimentary habitat, ANOVA was used to explore differences between blocks and treatments for sediment organic matter (OM) and total carbon (TC). No significant effects of the disturbance on sediment $\mathrm{OM}$ and TC were detected $(P>0.05$; Appendix C: Table C1), but there were significant differences between blocks $(P<0.05$; Appendix $C$ : Table $C 1)$. Habitat heterogeneity was thus accounted for when examining the disturbance response of individual measures of ecosystem function (Table 1) by using ANCOVA with $\mathrm{OM}$ (from the $0-3 \mathrm{~cm}$ sediment layer) as a continuous covariable. However, ANOVA was used to explore the patterns in chl $a$ and pigment degradation ratios. Data were, if necessary, $\log _{10}(x+1)$-transformed to fulfill requirements of normality, homogenous variances, and homogeneity of slopes. Any significant differences between treatments were further explored with Tukey's post hoc test. Univariate statistical analyses were performed with STATISTICA 10 (Statsoft 2003).

To explore the effects of increasing disturbance on ecosystem multifunctionality (EMF; all parameters in Table 1), multivariate analyses were used. An EMF resemblance matrix was created, in which betweensample similarities were based on Euclidean distances calculated on normalized variables that were, if neces- sary, log-transformed prior to normalization. Permutational ANOVA (PERMANOVA; Anderson et al. 2008) was used to detect differences between treatments, while accounting for environmental heterogeneity by using sediment $\mathrm{OM}$ as a continuous covariable. Although functional measures such as chl $a$ and pigment degradation ratios constitute a part of OM, their correlation to the total organic matter content in the sediment was either low (i.e., for degradation ratios, $r=$ $0.47, P<0.05, N=20$ ) or nonsignificant (chl $a, P>$ 0.05 ), and $\mathrm{OM}$ was thus allowed as a covariable for describing sediment properties in the $0-3 \mathrm{~cm}$ sediment layer. For a posteriori-wise comparisons between treatments, permutational $P$ values report the exact outcome of each individual comparison (Anderson et al. 2008). PERMDISP analysis was used to check if data showed homogeneity in multivariate dispersion among treatments. Distance-based redundancy analysis (dbRDA) was used to visualize the position of samples, as described by overall ecosystem multifunctionality in multivariate space, when constrained by the predictor variables "treatment" (i.e., categorical variable, binary form) and "organic matter" (continuous variable). The dbRDA vector overlay represents the multiple partial correlations (if $r>0.5$ ) of the explanatory variables to the dbRDA axes. In addition, functional parameters that were significantly related to the ordination axes $(-0.5 \geq r \geq 0.5, P<0.01)$ are marked on the ordination.

Distance-based linear models (DISTLM) were used to test how much of the overall change in ecosystem multifunctionality could be explained by (1) treatment, (2) environmental heterogeneity as represented by sediment organic matter (OM), and (3) by treatment after the effect of OM had been removed. Inclusion of predictor variables in the model was based on AIC criteria and a stepwise selection procedure. The results from the three models were used to calculate the amount of variability explained by treatment alone, OM alone, and the intersection of these effects, as per Borcard et al. (1992). An additional DISTLM analysis was run to explore the role of changes in benthic trait composition for EMF, while accounting for variability due to environmental heterogeneity $(\mathrm{OM})$ as well as the induced disturbance (treatment). Biological trait composition was chosen to represent changes in the macrofaunal community and encompassed the following traits: benthic feeding mode, mobility, size, bioturbation mode, and position in sediment. Differences in benthic trait composition between treatments were identified with one-way analysis of similarities (ANOSIM). Principal Coordinates Analysis (PCO) was run to produce variables representing changes in benthic trait composition; i.e., the first two axes of the community PCO that together explained $95.9 \%$ of the variability (Fig. 1). PCO as well as ANOSIM were based on Bray-Curtis similarity measures on untransformed trait data. In the additional DISTLM analysis, the $\mathrm{L}$ treatment (devoid of benthic fauna), and the 


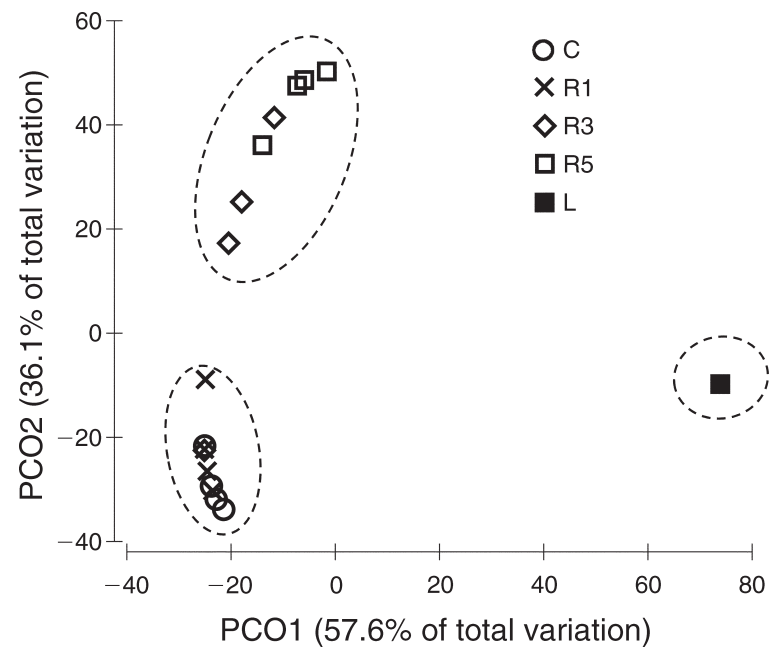

FIG. 1. Principal coordinates analysis (PCO) of the degradation pattern in benthic trait composition in response to increasing hypoxic disturbance. The following traits were included: benthic feeding mode, mobility, size, bioturbation mode, and position in sediment. The treatments were: C, control; R1, repeated 1; R3, repeated 3; R5, repeated 5; and L, long, uninterrupted period of hypoxia. PCO axes 1 and 2 together explain $93.8 \%$ of the variation. If the $\mathrm{L}$ treatment was excluded from the ordination (not shown) PCO1 explained $84.9 \%$ of the total variation, while PCO2 explained $11 \%$. Longterm hypoxia did result in azoic sediments, with no variation between treatments; therefore, the four replicates representing treatment $\mathrm{L}$ are indistinguishable and are represented by a single data point.

benthic functions $P_{\mathrm{s}}$ and $\mathrm{BP}_{c}$ were removed from the resemblance matrix describing EMF. Calculation of variation was done according to Anderson and Gribble (1998). Multivariate analyses were performed with the PRIMER PERMANOVA+ package (Anderson et al. 2008).

\section{RESULTS}

Hypoxic conditions were rapidly induced by the plastic sheets (within 1.5 days; cf. Villnäs et al. 2012). Reduced conditions were indicated by partially black sediment surfaces (likely caused by formation of ferrosulphides) in treatments exposed to repeated or uninterrupted periods of hypoxic stress (R3, R5, and L). When the plastic was removed, bottom water oxygen concentrations at disturbed plots increased rapidly, and did not differ from oxygen levels in the surrounding water column (on average $7.3 \mathrm{mg} \mathrm{O}_{2} / \mathrm{L}$ ) when sampling took place.

Individual parameters representing sediment ecosystem functions reacted differently to the increasing hypoxic stress (Table 1; Appendix C: Fig. C1, Table $\mathrm{C} 1)$. The benthic bioturbation potential $\left(\mathrm{BP}_{c}\right)$ was among the most severely affected ecosystem functions, as it was significantly reduced after three short periods of repeated hypoxia (R3; Table 1; Appendix C: Fig. C1, Table C1). Increasingly recurring disturbance events also caused gradual reductions in parameters representing primary and secondary biomass production (i.e., chl $a$ and $P_{\mathrm{s}}$ ), and these functions were significantly reduced in the R5 and L treatments compared to their levels in the control (Table 1; Appendix C: Table C1). The multivariate pattern in benthic trait composition (Fig. 1) supported the degradation pattern shown by $\mathrm{BP}_{\mathrm{c}}$ and $P_{\mathrm{s}}$. The PCO ordination (Fig. 1) shows that the benthic trait composition became degraded in treatments exposed to repeated hypoxic stress (i.e., R3, R5), while the R1 treatment did not differ significantly from the control treatment. The $\mathrm{L}$ treatment had no living fauna and thus deviated from all the other treatments. The thresholdlike difference between clusters of treatments (i.e., $\mathrm{C}$ and $\mathrm{R} 1$ vs. R3 and R5 vs. L) discerned from the ordination analysis (Fig. 1) was confirmed by plotting the PCO scores for axes 1 and 2, and through clustering analysis (not shown). Changes in benthic trait composition was supported by the changes observed in benthic community structure (i.e., abundance and biomass; Appendix D: Fig. D1). The degradation pattern observed for primary production estimates was supported by the phaeophytins vs. chl $a$ ratio, describing a higher pigment degradation ratio in the $\mathrm{R} 5$ and $\mathrm{L}$ treatments compared to undisturbed sediments. However, a significant increase in the diatoxanthin vs. diadinoxanthin ratio was only observed in the L treatment (Table 1; Appendix C: Fig. C1, Table $\mathrm{C} 1$ ). There was a slightly decreasing trend in pigment degradation products with repeated disturbance, but no significant difference was observed between treatments (ANOVA; $P>0.05$ ).

Sediment oxygen consumption and fluxes of $\mathrm{PO}_{4}{ }^{3-}$, $\mathrm{Fe}^{2+}$, and $\mathrm{NH}_{4}^{+}$were significantly reduced from control levels only in the L treatment (Table 1; Appendix C: Fig. $\mathrm{C} 1$, Table C1). Analysis of sediment $\mathrm{PO}_{4}{ }^{3-}$ sorption supported the observed flux pattern of sediment phosphate, i.e., the reoxidized sediment of the $\mathrm{L}$ treatment had the highest sorption capability. Interestingly, the analysis indicated that the $\mathrm{PO}_{4}{ }^{3-}$ sorption capability was already affected in the R3 treatment (Appendix B: Fig. B1b). The phosphate and iron fluxes correlated $(r=0.715, P<0.001)$, and both parameters were negatively related to the sediment $\mathrm{O}_{2}$ flux $(r \leq$ $-0.54, P \leq 0.01$ ), while no significant relation was observed between these parameters and the flux of dissolved $\mathrm{Si}(P>0.05)$. The $\mathrm{NH}_{4}{ }^{+}$flux had a positive correlation with macrobenthic biomass $(r=0.637, P=$ 0.003). Three of the parameters representing sediment nutrient exchange (fluxes of dissolved $\mathrm{Si}$, nitrification, and denitrification) were primarily regulated by habitat heterogeneity $(\mathrm{OM})$, and were not significantly affected by the disturbance regime (Table 1; Appendix C: Fig. C1, Table C1). The flux of dissolved Si correlated with the pigment degradation products diatoxanthin $(r=$ $0.745, P<0.001$ ), phaeophytin $a$ and pyrophaeophytin $a(r>0.6, P<0.01)$.

In contrast to responses observed in single ecosystem functions, patterns in ecosystem multifunctionality were 
TABle 2. Results from PERMANOVA and PERMDISP examining the effects of increasing hypoxic disturbance (i.e., treatments) on ecosystem multifunctionality.

\begin{tabular}{lrrcr}
\hline \hline PERMANOVA & df & \multicolumn{1}{c}{ SS } & pseudo- $F$ & $P($ perm $)$ \\
\hline Organic matter & 1 & 41.101 & 8.351 & $<0.001$ \\
Treatment & 4 & 117.990 & 5.993 & $<0.001$ \\
Residuals & 14 & 68.907 & & \\
Total & 19 & 228.000 & & \\
PERMDISP & 4,15 & & 0.900 & 0.661 \\
Treatment & 4,15 & & & \\
\hline
\end{tabular}

Notes: Sediment organic matter was included as a covariable in the analysis. The ecosystem function matrix included all ecosystem functions given in Table $1 . P$ values were obtained for predictor variables by 9999 permutations, $P$ (perm).

more sensitive, indicating that the system was slightly affected already after a single three-day pulse of hypoxic stress (PERMANOVA, C-R $1, P=0.048$; Tables 2 and 3). PERMANOVA distinguished significant differences in ecosystem multifunctionality between most treatments, except for the R3 treatment that did not deviate from the $\mathrm{C}, \mathrm{R} 1$, or $\mathrm{R} 5$ treatment $(P>0.05$; Tables 2 and $3)$. This could be due to the variation within the sedimentary habitat, as depicted by sediment organic matter content, which affected ecosystem multifunctionality $(P<0.001$; Tables 2 and 3$)$ and increased the variability within treatments in multivariate space (Fig. 2). However, pairwise $t$ values increased when comparing undisturbed sediments to those exposed to increasingly recurring disturbance, indicating a growing difference between the control and the disturbed treatments as the stress became more severe (Table 3 ). When rerunning the analysis (excluding the $\mathrm{L}$ treatment and the zoobenthic variables $P_{\mathrm{s}}$ and $\mathrm{BP}_{\mathrm{c}}$ ), similar differences between treatments were observed as with the full set of variables (cf. Tables 2 and 3 and Appendix C: Table C2).

The dbRDA ordination confirmed the results obtained by PERMANOVA and distinguished a sequential degradation pattern in ecosystem multifunctionality with increasing disturbance (as illustrated by the horizontal vector overlay in Fig. 2), while variation due to environmental heterogeneity (i.e., OM) separated blocks with higher organic matter from those with lower levels. Correlations between single ecosystem functions and dbRDA axes 1 (Pearson, $-0.5>r>0.5, P<0.01$ ) confirmed that while most functions (i.e., $P_{\mathrm{s}}, \mathrm{BP}_{\mathrm{c}}, \mathrm{chl} a$, $\mathrm{O}_{2}$ consumption, and fluxes of $\mathrm{Fe}^{2+}, \mathrm{PO}_{4}{ }^{3-}$, and $\mathrm{NH}_{4}{ }^{+}$) were reduced with increasing disturbance, pigment degradation ratios increased. However, functions such as nitrification, denitrification, and sediment fluxes of silicate correlated with dbRDA axis 2, which was directed by the sediment organic matter content (Fig. 2).

Distance-based linear models (DISTLM) and subsequent variation partitioning (Table 4) suggested that a large part of the observed variation in ecosystem multifunctionality (EMF) was due to the increasing hypoxic disturbance (i.e., 52\%), while sediment organic matter explained $19 \%$ of the total variation and $30 \%$ remained unexplained (Fig. 3A). When including benthic community trait composition as an explanatory variable in the DISTLM analysis (Fig. 3B), sediment organic matter explained $17 \%$ of the variation in EMF, while disturbance explained $15 \%$ and $6 \%$ was explained by the intersection between these two parameters. Alone, the trait composition of the macrobenthic fauna explained only $9 \%$ of the variation in sediment ecosystem functioning, but the intersection between benthic trait composition and disturbance was significant, $31 \%$, emphasizing that disturbance-induced changes in benthic biological traits was of major importance for overall ecosystem functioning.

\section{Discussion}

Recurrent patchy disturbances are characteristic of most natural ecosystems (Sousa 2001), but the frequency of such disturbances is increasing with the expansion of human activities (Bengtsson et al. 2003). The response of ecosystem functions to single pulse disturbances may represent trajectories of either short-term change or more continuous degradation (Glasby and Underwood 1996, Lake 2000). An increasing recurrence of pulse disturbances is likely to have more severe consequences for ecosystem functioning as the transition from pulse to press disturbances is expected to reduce ecosystem resilience (Bengtsson et al. 2003). Ultimately, the consequences of repeated disturbances will depend on the ecological memory of the system (i.e., the "network of species, their dynamic interactions between each other and the environment, and the combinations of structures that make reorganization after disturbance possible"; Bengtsson et al. 2003). This ecological memory might to some extent buffer against repeated disturbances, but when it is reduced (i.e., the shape of the stability domain changes), there is an increased risk that the ecosystem will turn into an alternative state, and that ecosystem functions will become degraded (Scheffer et

TABLE 3. Pairwise a posteriori comparisons for PERMANOVA and PERMDISP describing differences in ecosystem multifunctionality between treatments (cf. Table 2).

\begin{tabular}{|c|c|c|c|c|}
\hline \multirow{2}{*}{$\frac{\text { Pairwise tests }}{\text { Treatment }}$} & \multicolumn{2}{|c|}{ PERMANOVA } & \multicolumn{2}{|c|}{ PERMDISP } \\
\hline & $t$ & $P($ perm $)$ & $t$ & $P($ perm $)$ \\
\hline $\mathrm{C}$ and $\mathrm{R} 1$ & 1.515 & 0.048 & 0.080 & 1.000 \\
\hline $\mathrm{C}$ and $\mathrm{R} 3$ & 1.745 & 0.056 & 0.631 & 0.598 \\
\hline $\mathrm{C}$ and $\mathrm{R} 5$ & 2.816 & 0.027 & 0.033 & 0.973 \\
\hline $\mathrm{C}$ and $\mathrm{L}$ & 4.014 & 0.013 & 1.114 & 0.550 \\
\hline $\mathrm{R} 1$ and $\mathrm{R} 3$ & 1.262 & 0.158 & 0.968 & 0.454 \\
\hline $\mathrm{R} 1$ and $\mathrm{R} 5$ & 2.168 & 0.022 & 0.351 & 0.599 \\
\hline $\mathrm{R} 1$ and $\mathrm{L}$ & 3.469 & 0.012 & 2.699 & 0.029 \\
\hline $\mathrm{R} 3$ and $\mathrm{R} 5$ & 1.385 & 0.098 & 1.188 & 0.405 \\
\hline R3 and L & 2.273 & 0.006 & 0.599 & 0.683 \\
\hline $\mathrm{R} 5$ and $\mathrm{L}$ & 1.767 & 0.013 & 3.432 & 0.031 \\
\hline
\end{tabular}

Notes: Sediment organic matter was included as a covariable in the analysis. The ecosystem function matrix included all ecosystem functions given in Table 1. 


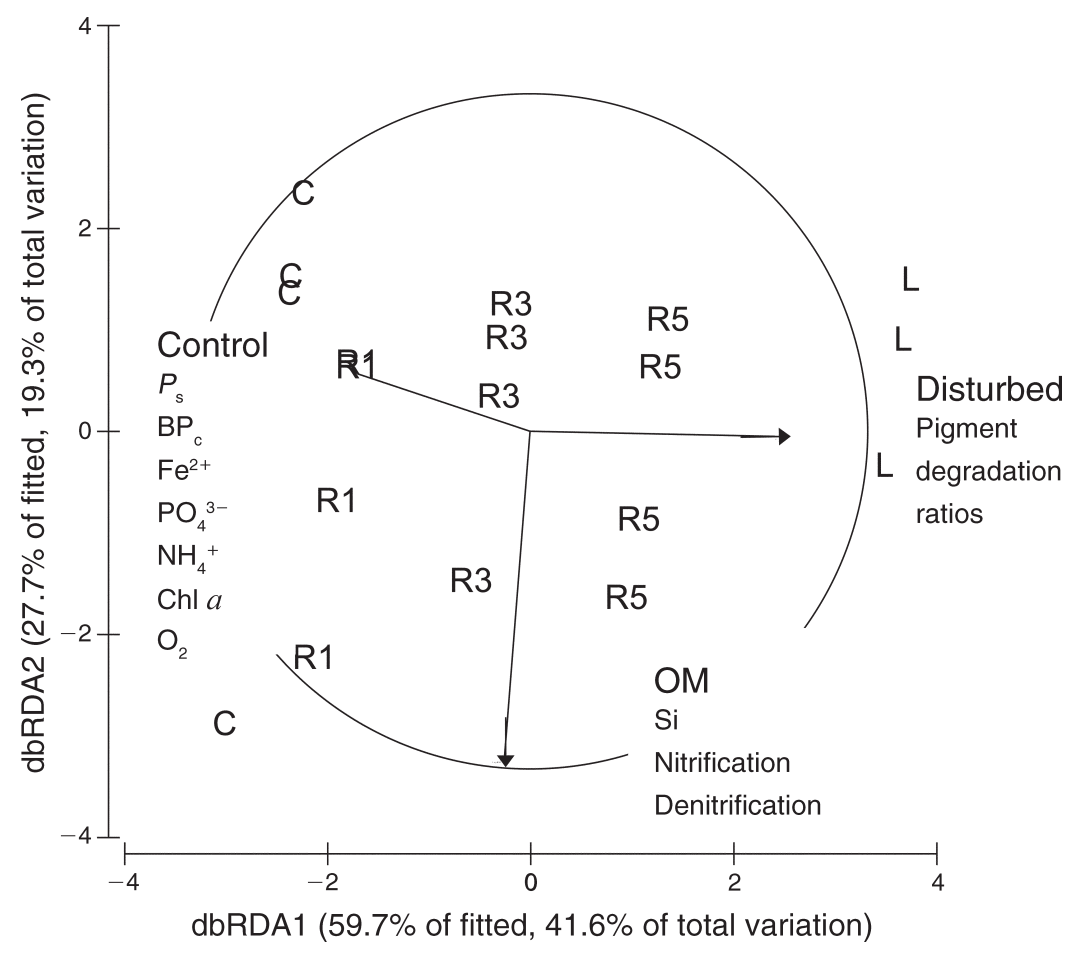

FIG. 2. The dbRDA (distance-based redundancy analysis) ordination for multiple ecosystem functions vs. the fitted explanatory variables habitat heterogeneity $(\mathrm{OM})$ and increasing hypoxic disturbance (treatment). Vector overlays (shown if $>0.5)$ represent multiple partial correlations of the explanatory variables with the dbRDA axes. Disturbance (horizontal vector) and organic matter (vertical vector) are increasing in the direction of the arrows. Ecosystem functions, showing significant correlations with dbRDA axes 1 and 2 (Pearson, $-0.5>r>0.5, P<0.01$ ) are marked in the direction toward which they are increasing. Abbreviations are: $P_{\mathrm{s}}$, secondary somatic production; $\mathrm{BP}_{\mathrm{c}}$, benthic bioturbation potential; $\mathrm{O}_{2}$, sediment oxygen consumption (i.e., influx); OM, organic matter.

al. 2001, Bengtsson et al. 2003, Ives and Carpenter 2007). Consequently, there is an urgent need to assess ecosystem vulnerability against repetitive disturbances, and evaluate the possible consequences for ecosystem functioning.

By increasing the occurrence of repeated hypoxia to a coastal, sedimentary ecosystem, we showed that most of the examined ecosystem functions were gradually degraded in response to the hypoxic stress. Thus, the increasing number of repeated pulse disturbances (R1, R3, R5) gradually moved the system closer to a press response (as represented by the L treatment; Fig. 2). However, individual ecosystem functions differed in their disturbance response (cf. Appendix C: Fig. C1), and responses in individual functions did not represent the joint response of multiple ecosystem functions. The degradation in ecosystem multifunctionality was evident at an earlier stage than apparent from analysis of single ecosystem functions, as it was induced after one short pulse of hypoxia that reduced ecosystem resistance to further hypoxic perturbations. This implies that a range of ecosystem functions (in our case both biological and biogeochemical processes of the system representing ecosystem metabolism, elemental cycling, biomass production, organic matter transformation, and physical structuring; cf. Table 1; Giller et al. 2004) should be taken into consideration when assessing the consequences of disturbances, in order to aid management and conservation of a desired ecosystem status. In addition to disturbance recurrence, habitat heterogeneity as well as disturbance-induced changes in benthic trait composition were essential factors in predicting the response in ecosystem multifunctionality. Our results emphasize that the response and resistance of ecosystem functions to disturbances should be evaluated under natural environmental conditions, as there is a high level of connectivity and interactions between the multiple elements of marine coastal ecosystems (Townsend et al. 2011).

\section{Responses in individual ecosystem functions}

Hypoxia affects sediment ecosystem functions through different processes (e.g., by altering diagenetic pathways, reoxidation processes, organic matter degradation, and organism survival; Kristensen [2000], Middelburg and Levin [2009]). In general, we found that the increasing hypoxic stress had the most severe effects on biotic ecosystem functions (i.e., bioturbation, primary and secondary biomass production, pigment degradation), while measures of sediment oxygen consumption 
TABLE 4. Results of variation partitioning analysis (DISTLM) quantifying the marginal and sequential (pure) effects of sediment organic matter (continuous variable) and treatment (categorical variable) on ecosystem multifunctionality. A reduced set of ecosystem functions and treatments was used when adding benthic trait composition (as explained by principal coordinates analysis, i.e., PCO axes 1and 2; cf. Fig. 1) as an explanatory variable in the analysis.

\begin{tabular}{lccccrr}
\hline \hline Source of variation & $R^{2}$ & df res & df regr & Pseudo- $F$ & SS (trace) & $P($ perm $)$ \\
\hline Predictors & & & & & & \\
$\quad$ OM & 0.180 & 18 & 2 & 3.958 & 41.101 & 0.006 \\
Treatment & 0.510 & 15 & 5 & 3.898 & 116.210 & $<0.001$ \\
Total & 0.698 & 14 & 6 & 6.465 & 159.090 & $<0.001$ \\
Pure OM & 0.188 & 14 & 6 & 8.712 & 42.882 & $<0.001$ \\
Pure treatment & 0.518 & 14 & 6 & 5.993 & 117.990 & $<0.001$ \\
& & & & & & \\
OM & 0.375 & 14 & 2 & 8.387 & 46.731 & $<0.001$ \\
Treatment & 0.273 & 12 & 4 & 1.504 & 34.083 & 0.125 \\
Benthic traits & 0.241 & 13 & 3 & 2.065 & 30.076 & 0.044 \\
Total & 0.770 & 9 & 7 & 5.029 & 96.074 & $<0.001$ \\
Pure OM & 0.285 & 9 & 7 & 11.146 & 35.493 & $<0.001$ \\
Pure treatment & 0.196 & 9 & 7 & 2.560 & 24.456 & 0.004 \\
Pure benthic traits & 0.129 & 9 & 7 & 2.531 & 16.119 & 0.024 \\
\hline
\end{tabular}

Notes: Abbreviations for df are: res, residual; and regr, regression.

and nutrient exchange (i.e., $\mathrm{PO}_{4}{ }^{3-}, \mathrm{Fe}^{2+}, \mathrm{NH}_{4}{ }^{+}$) were significantly reduced only after 30 days of uninterrupted hypoxic disturbance. Functions such as nitrification, denitrification, as well as the efflux of silicate were foremost directed by habitat heterogeneity (cf. Table 1). Oxidation-reduction reactions (early diagenesis) are reversible and might recover quickly. For example, our results indicate that a $24-\mathrm{h}$ period of reoxidation was enough to oxidize part of the $\mathrm{Fe}$ compounds at the sediment surface, affecting binding of $\mathrm{PO}_{4}{ }^{3-}$ to the sediment. In the reoxygenated sediments of the $\mathrm{R} 3$ treatment, some iron-bound $\mathrm{PO}_{4}{ }^{3-}$ remained in the sediment and hindered sorption of added $\mathrm{PO}_{4}{ }^{3-}$ (Appendix B: Fig. B1b). Continuous hypoxia (L), however, resulted in leakage of $\mathrm{PO}_{4}{ }^{3-}$ out from the sediment, which could be seen as more efficient $\mathrm{PO}_{4}{ }^{3-}$ sorption to reoxidized sediment (i.e., to vacant binding sites) (Appendices B and C: Figs. B1b, C1). Prolonged hypoxia resulted also in negative flux of $\mathrm{Fe}^{2+}$, which can indicate its capture to the solid phase as ferrosulphide. Overall, it seems as short, repeated hypoxic periods might have a limited direct effect on biogeochemical functions that foremost depend on diffusion processes, and that these functions might rapidly recover through reoxidation processes in surface sediments when oxic conditions reestablish (Middelburg and Levin 2009).

Functions affected by microphytobenthos have shown resilience toward hypoxic disturbance (Larson and
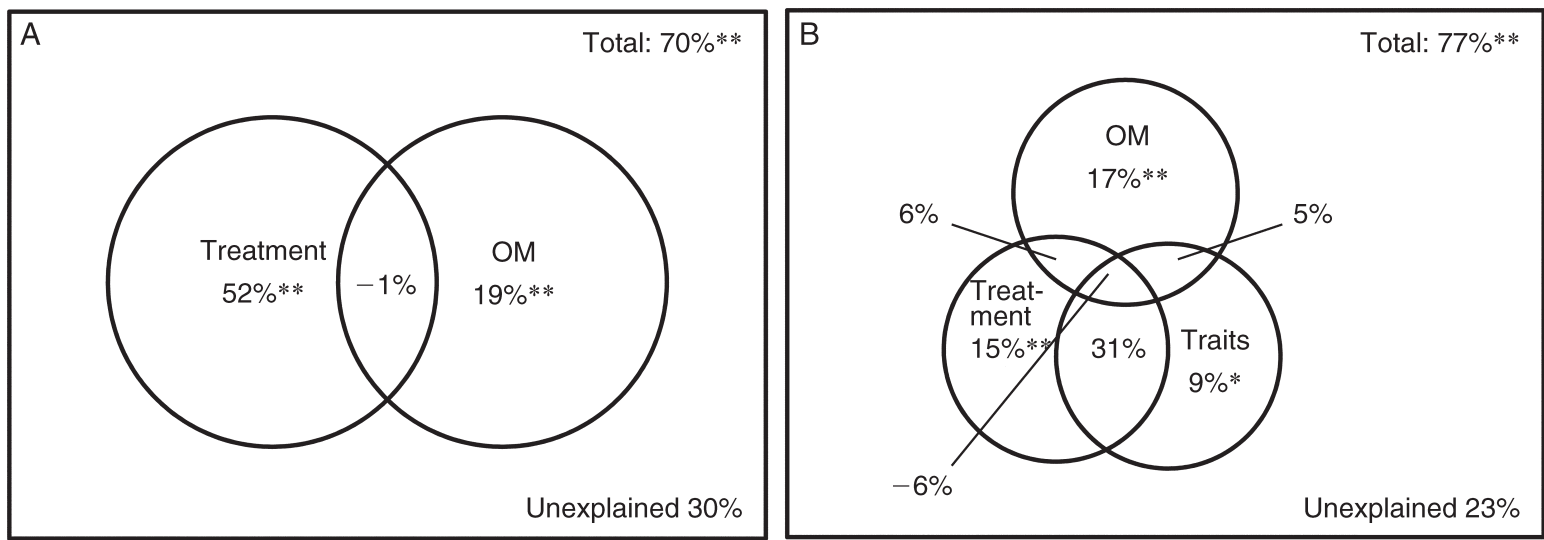

FIG. 3. Diagrams presenting the results of variation partitioning analysis performed on data describing ecosystem multifunctionality. For panel (A), overall ecosystem multifunctionality, the diagram represents the unique and shared contribution of habitat heterogeneity $(\mathrm{OM})$ and increasing hypoxic disturbance (treatment), as well as the percentage of unexplained variance. For a reduced set of treatments (L excluded) and functions $\left(P_{\mathrm{s}}\right.$ and $\mathrm{BP}_{\mathrm{c}}$ excluded), panel $(\mathrm{B})$ represents the contributions of habitat heterogeneity, treatment, and benthic trait composition (as explained by principal coordinates analysis, i.e., PCO axes 1 and 2; cf. Fig. 1).

$* P<0.05 ; * * P<0.001$. 
Sundbäck 2008). However, in our study the microphytobenthic biomass was gradually degraded in response to the dark, hypoxic conditions, and was not able to recover from losses between periods of stress. Hence, processes provided by these autotrophs, such as sediment oxygenation, nutrient uptake, and food supply, might become impaired by repeated hypoxic events and become further counteracted by mineralization processes of dead microalgae. Indeed, we observed increases in pigment degradation ratios with the increased stress, and our results support observations that microphytobenthic pigment degradation in dark conditions occurs within days or weeks (Veuger and Van Oevelen 2011). However, not only darkness, but also direct oxygen stress has been shown to decrease benthic microalgae and their primary production (Conley et al. 2007), but in our experiment, we could not separate the influences of these two stressors on the benthic primary producers. Importantly, pigment degradation coincided with a significant positive effect on the efflux of silicate, indicating ongoing degradation of diatom material.

The benthic fauna may survive and recover from brief hypoxic periods (hours to days) possibly retaining macrobenthic functions as species differ in their resistance to hypoxia (Vaquer-Sunyer and Duarte 2008). We did, however, observe a gradual degradation of macrobenthic functions such as secondary biomass production and bioturbation with repeated hypoxic disturbance. When exposed to increasing hypoxic stress, the degradation pattern in benthic community functions can be more directed by losses in faunal abundance and biomass (i.e., dominance alterations), than by extinction of individual species or traits (Villnäs et al. 2012). This was also indicated in this study when comparing changes in benthic biological traits with changes in the abundance and biomass composition of the fauna (cf. Fig. 1 and Appendix D). Importantly, the multivariate analysis indicated that the repeated disturbance caused threshold-like responses in the trait composition of the macrobenthic community (cf. Andersen et al. 2009). The multivariate pattern of benthic traits (i.e., benthic feeding mode, mobility, size, bioturbation mode, and position in sediment) showed a clear separation if comparing treatments exposed to no, or a single pulse (C, R1) of hypoxic disturbance vs. treatments with repeated hypoxic stress (R3, R5). Similarly, the PCO analysis clearly separated the $\mathrm{L}$ treatment, which had no benthic fauna, from the others (Fig. 1). Our results are in line with early studies showing that increasing frequencies of disturbance do impair benthic communities (Dayton 1971, Sousa 1979). The fact that the repeated hypoxic disturbance severely impaired benthic trait composition has long-term consequences, as benthic communities can show a delayed or even hysteresis-like recovery from such disturbances (Diaz and Rosenberg 2008).

Although natural systems are inherently variable in time and space, this variability is rarely considered when assessing ecosystem functioning (Dyson et al. 2007). By performing a field experiment, we encompassed significant habitat heterogeneity in our study, exemplified by differing sediment properties between replicate blocks. Habitat heterogeneity (i.e., variations in sediment organic matter) alone explained $17-19 \%$ of the variation in ecosystem multifunctionality, and sediment organic matter content was the main explanatory variable for ecosystem functions such as nitrification and denitrification rates. This was probably due to the strong association of nitrifiers and denitrifiers to the organicrich fraction of the sediment (Jäntti et al. 2011). Furthermore, the insignificant effects of hypoxic stress on sediment nitrification rates might also be explained by the ability of nitrifiers to survive periods of inactivity when exposed to hypoxia and to rapidly recover their activities when oxic conditions reestablish (Henriksen et al. 1981). That no evident effects of hypoxic stress could be observed on sediment denitrification rates is in line with results reported by Hietanen and Lukkari (2007), who found no change in sediment denitrification rates after two weeks of anoxia. Similarly, differences in sediment properties also affected the sorption of $\mathrm{PO}_{4}{ }^{3-}$, as finer sediments provided a higher total particle surface area for $\mathrm{PO}_{4}{ }^{3-}$ sorption (cf. Appendix B: Fig. B1a). Our results are in agreement with studies finding that habitat heterogeneity is an important predictor modifying ecosystem functions, either through exerting direct effects on ecosystem processes (Hooper et al. 2012, Maestre et al. 2012) or by interacting with biotic communities (Dyson et al. 2007, Tylianakis et al. 2008). Due to logistical constraints and hence limited replication, we could not explore the interactions between habitat differences and different disturbance levels, although this information would be essential for predicting the effects of disturbances on larger spatial scales. This is recommended in future research, as it is evident that spatial heterogeneity is of importance when considering ecosystem functions such as nutrient cycling at larger scales (Dyson et al. 2007).

\section{Resistance of multiple ecosystem functions: implications for ecosystem resilience}

Disturbances can affect ecosystems in complex, nonlinear, and often unpredictable ways. Hence, ecosystem responses to increasing disturbance dynamics have been classified into three general categories: scaleindependent, continuous, and threshold-like (Scheffer et al. 2001, Suding and Hobbs 2009). Analyses of longterm data from hypoxia-prone areas have suggested that ecosystems might respond to hypoxia in a threshold-like manner (Conley et al. 2007, 2009). The resilience of an ecosystem to hypoxia becomes reduced when important buffers supporting the maintenance of oxic conditions (e.g., electron acceptors and bioturbation) become depleted (Conley et al. 2009). Once the threshold to an anaerobic state is exceeded, there is an accumulation of reduced components in the system (i.e., $\mathrm{H}_{2} \mathrm{~S}$ ) that 
consume any diffusing oxygen and buffer sediment reoxygenation, which increases ecosystem susceptibility to further hypoxic stress (Conley et al. 2009). The results of our study suggested a continuous, negative response in ecosystem multifunctionality to repeated hypoxic stress, and no abrupt threshold that would have indicated the transfer from oxic to anoxic processes was detected (cf. Fig. 1). That we could not identify a sudden threshold in the overall response was probably due to differences in the resistance of individual ecosystem functions, and because of the partial recovery of some biogeochemical functions during intermittent reoxygenation processes. Despite these differences, the overall degradation pattern in ecosystem functioning indicated, at an earlier stage than single ecosystem functions, that ecosystem resistance became reduced and that the system became increasingly vulnerable with repeated hypoxic stress. Such gradual degradation patterns are important to identify, as they diminish ecosystem resilience and the stability domain of the system (Scheffer et al. 2001). Hence, consideration of disturbance-induced changes in multiple ecosystem functions serves as a warning signal for losses of the adaptive capacity of an ecosystem, and might in an early stage provide information to managers and policy makers when remediation efforts should be initiated.

\section{Consequences of recurring disturbance for biodiversity and ecosystem multifunctionality}

A large body of research emphasizes the importance of biodiversity for sustaining the properties and processes of ecosystems (Cardinale et al. 2012, Naeem et al. 2012). However, from an ecosystem management point of view, there is an increasing need to expand this concept and consider the underlying causes for changes in biodiversity and their relative importance for changes in ecosystem functioning (Srivastava and Vellend 2005). Our results suggested that the increasing hypoxic disturbance was the major explanatory factor for the variation in ecosystem multifunctionality (Fig. 3A), and that the repetitive disturbance also directed the degradation of the macrobenthic community (Fig. 1; Appendix D). Importantly, when considering the trait composition of the macrobenthic community as an additional predictor variable for overall ecosystem functioning, we found that the amount of variability in ecosystem multifunctionality explained by the disturbance-induced changes in the benthic community was comparable to the amount explained by disturbance, and that there was a large overlap (31\%) between these variables (Fig. 3B). This indicates that the impairment of natural biotic communities might account for a substantial proportion of the changes in ecosystem multifunctionality during disturbance scenarios.

Ecosystem resilience is the result of complex interactions and feedbacks between multiple ecosystem functions and properties (Thrush et al. 2012). Nevertheless, from a biodiversity perspective, disturbance-induced changes in biotic communities can have severe implications for ecosystem resilience, as species influence a broad range of ecosystem functions (Thrush et al. 2009, 2012, Townsend et al. 2011), and might have a delayed recovery after ceased disturbance in comparison to other ecosystem components. Our study suggests that benthic traits determining ecosystem functions such as physical structuring and secondary biomass production are important for a healthy ecosystem, as they influence a range of ecosystem functions, including ecosystem metabolism, elemental cycling, and primary production, as well as organic matter transformation (e.g., Norkko et al. 2006, Middelburg and Levin 2009, Josefson et al. 2012, Thrush et al. 2012). The degradation of benthic biological traits observed in our study was thus likely to have a profound impact on ecosystem resilience compared to the other functions investigated, as it impaired the adaptive capacity of the system (cf. Bengtsson et al. 2003). Many ecosystems are experiencing gradual degradation, which results in slowly shifting baselines and reduced expectations (Dayton et al. 1998, Villnäs and Norkko 2011). Although ecosystem functionality is determined by the present state of the environment and the biota, our results emphasize that the disturbance history of a system is a key element for understanding the vulnerability of ecosystems to further degradative change. Importantly our results suggest that even small, but recurring, disturbances can reduce ecosystem resilience by changing its overall functionality, and transfer the system closer to continuous degradation.

\section{ACKNOWLEDGMENTS}

This work was funded by the BONUS+ project HYPER, the Walter and Andrée de Nottbeck Foundation, Onni Talaan Säätiö, and the Academy of Finland (project numbers 114076 and 110999 ). We thank S. Valanko, A. Jansson, L. Avellan, and J. Gammal for field assistance, B. L. Møller for HPLC analyses of pigments, and Tvärminne Zoological Station for providing excellent research facilities. We thank D. Raffaelli and three anonymous reviewers for insightful comments on the manuscript.

\section{Literature Cited}

Andersen, T., J. Carstensen, E. Hernández-García, and C. M. Duarte. 2009. Ecological thresholds and regime shifts: approaches to identification. Trends in Ecology and Evolution 24:49-57.

Anderson, M. J., R. N. Gorley, and K. R. Clarke. 2008. PERMANOVA+ for PRIMER: guide to software and statistical methods. PRIMER-E, Plymouth, UK.

Anderson, M. J., and N. A. Gribble. 1998. Partitioning the variation among spatial, temporal and environmental components in a multivariate data set. Australian Journal of Ecology 23:158-167.

Bender, E. A., T. J. Case, and M. E. Gilpin. 1984. Perturbation experiments in community ecology: theory and practice. Ecology 65:1-13.

Bengtsson, J., P. Angelstam, T. Elmqvist, U. Emanuelsson, C. Folke, M. Ihse, F. Moberg, and M. Nyström. 2003. Reserves, resilience and dynamic landscapes. Ambio 6:389-396.

Bonsdorff, E., and T. H. Pearson. 1999. Variation in the sublittoral macrozoobenthos of the Baltic Sea along environmental gradients: a functional-group approach. Australian Journal of Ecology 24:312-326. 
Borcard, D., P. Legendre, and P. Drapeau. 1992. Partialling out the spatial component of ecological variation. Ecology 73: 1045-1055.

Bremner, J., S. I. Rogers, and C. L. J. Frid. 2003. Assessing functional diversity in marine benthic ecosystems: a comparison of approaches. Marine Ecology Progress Series 254:1125.

Cardinale, B. J., et al. 2012. Biodiversity loss and its impact on humanity. Nature 486:59-67.

Conley, D. J., J. Carstensen, G. Ærtebjerg, P. B. Christensen, T. Dalsgaard, J. L. S. Hansen, and A. B. Josefson. 2007. Long-term changes and impacts of hypoxia in Danish coastal waters. Ecological Applications 17:S165-S184.

Conley, D. J., et al. 2011. Hypoxia is increasing in the coastal zone of the Baltic Sea. Environmental Science and Technology 45:6777-6783.

Conley, D. J., J. Carstensen, R. Vaquer-Sunyer, and C. M. Duarte. 2009. Ecosystem thresholds with hypoxia. Hydrobiologia 629:21-29.

Cumming, G. S., G. Barnes, S. Perz, M. Schmink, K. E. Sieving, J. Southworth, M. Binford, R. D. Holt, C. Stickler, and T. Van Holt. 2005. An exploratory framework for the empirical measurement of resilience. Ecosystems 8:975-987.

Dayton, P. K. 1971. Competition, disturbance, and community organization: the provision and subsequent utilization of space in a rocky intertidal community. Ecological Monographs 41:351-389.

Dayton, P. K., M. J. Tegner, P. B. Edwards, and K. L. Riser. 1998. Sliding baselines, ghosts, and reduced expectations in kelp forest communities. Ecological Applications 8:309-322.

Diaz, R. J., and R. Rosenberg. 2008. Spreading dead zones and consequences for marine ecosystems. Science 321:926-929.

Dyson, K. E., M. T. Bulling, M. Solan, G. Hernandez-Milian, D. G. Raffaelli, P. C. L. White, and D. M. Paterson. 2007. Influence of macrofauna assemblages and environmental heterogeneity on microphytobenthic production in experimental systems. Proceedings of the Royal Society B 274: $2547-2554$.

Eby, L. A., L. B. Crowder, C. M. McClellan, C. H. Peterson, and M. J. Powers. 2005. Habitat degradation from intermittent hypoxia: impacts on demersal fishes. Marine Ecology Progress Series 291:249-261.

Fish, J. D., and S. Fish. 1996. A student's guide to the seashore. Second edition. Cambridge University Press, Cambridge, UK.

Gamfeldt, L., H. Hillebrand, and P. R. Jonsson. 2008. Multiple functions increase the importance of biodiversity for overall ecosystem functioning. Ecology 89:1223-1231.

Giller, P. S., et al. 2004. Biodiversity effects on ecosystem functioning: emerging issues and their experimental test in aquatic environments. Oikos 104:423-436.

Glasby, T. M., and A. J. Underwood. 1996. Sampling to differentiate between pulse and press perturbations. Environmental Monitoring and Assessment 42:241-252.

Hagy, J. D., W. R. Boynton, C. W. Keefe, and K. V. Wood. 2004. Hypoxia in Chesapeake Bay, 1950-2001: long-term change in relation to nutrient loading and river flow. Estuaries 27:634-658.

Hector, A., and R. Bagchi. 2007. Biodiversity and ecosystem multifunctionality. Nature 448:188-191.

Henriksen, K., J. I. Hansen, and T. H. Blackburn. 1981. Rates of nitrification, distribution of nitrifying bacteria, and nitrate fluxes in different types of sediment from Danish waters. Marine Biology 61:299-304.

Hewitt, J. E., S. F. Thrush, and P. K. Dayton. 2008. Habitat variation, species diversity and ecological functioning in a marine system. Journal of Experimental Marine Biology and Ecology 366:116-122.

Hietanen, S., and K. Lukkari. 2007. Effects of short-term anoxia on benthic denitrification, nutrient fluxes and phosphorus forms in coastal Baltic sediment. Aquatic Microbiology and Ecology 49:293-302.
Hillebrand, H., and B. Matthiessen. 2009. Biodiversity in a complex world: consolidation and progress in functional biodiversity research. Ecology Letters 12:1405-1419.

Holling, C. S. 1973. Resilience and stability of ecological systems. Annual Review of Ecology and Systematics 4:1-23.

Hooper, D. U., E. C. Adair, B. J. Cardinale, J. E. K. Byrnes, B. A. Hungate, K. L. Matulik, A. Gonzalez, J. E. Duffy, L. Gamfeldt, and M. I. Connor. 2012. A global synthesis reveals biodiversity loss as a major driver of ecosystem change. Nature 486:105-108.

Hooper, D. U., et al. 2005. Effects of biodiversity on ecosystem functioning; a consensus of current knowledge. Ecological Monographs 75:3-35.

Ives, A. R., and S. R. Carpenter. 2007. Stability and diversity of ecosystems. Science 6:58-62.

Jäntti, H., F. Stange, E. Leskinen, and S. Hietanen. 2011. Seasonal variation in nitrification and nitrate-reduction pathways in coastal sediments in the Gulf of Finland, Baltic Sea. Aquatic Microbial Ecology 63:171-181.

Josefson, A. B., J. Norkko, and A. Norkko. 2012. Burial and decomposition of plant pigments in surface sediments of the Baltic Sea: role of oxygen and benthic fauna. Marine Ecology Progress Series 455:33-49.

Keeling, R. F., A. Körtzinger, and N. Gruber. 2010. Ocean deoxygenation in a warming world. Annual Review of Marine Science 2:199-229.

Koski-Vähälä, J., and H. Hartikainen. 2001. Assessment of the risk of phosphorus loading due to resuspended sediment. Journal of Environmental Quality 30:960-966.

Kristensen, E. 2000. Organic matter diagenesis at the oxic/ anoxic interface in coastal marine sediments, with emphasis on the role of burrowing animals. Hydrobiologia 426:1-24.

Laine, A. O., A.-B. Andersin, S. Leiniö, and A. F. Zuur. 2007. Stratification-induced hypoxia as a structuring factor of macrozoobenthos in the open Gulf of Finland (Baltic Sea). Journal of Sea Research 57:65-77.

Lake, P. S. 2000. Disturbance, patchiness, and diversity in streams. Journal of the North American Benthological Society 19:573-592.

Lappalainen, A., and P. Kangas. 1975. Littoral benthos of the Northern Baltic Sea II. Interrelationships of wet, dry and ash-free dry weights of macrofauna in the Tvärminne area. Internationale Revue der gesamten Hydrobiologie und Hydrographie 60:207-312.

Larson, F., and K. Sundbäck. 2008. Role of microphytobenthos in recovery of functions in a shallow-water sediment system after hypoxic events. Marine Ecology Progress Series $357: 1-16$

Levin, L. A. 2003. Oxygen minimum zone benthos: adaptation and community response to hypoxia. Oceanography and Marine Biology 41:1-45.

Lohrer, A. M., S. F. Thrush, and M. M. Gibbs. 2004. Bioturbators enhance ecosystem function through complex biogeochemical interactions. Nature 431:1092-1095.

Maestre, F. T., et al. 2012. Plant species richness and ecosystem multifunctionality in global drylands. Science 335:214-217.

Michener, W. K., T. J. Baerwald, P. Firth, M. A. Palmer, J. L. Rosenberger, E. A. Sandlin, and H. Zimmerman. 2001. Defining and unravelling biocomplexity. BioScience 51:10181023.

Middelburg, J. J., and L. A. Levin. 2009. Coastal hypoxia and sediment biogeochemistry. Biogeosciences 6:1273-1293.

Naeem, S., J. E. Duffy, and E. Zavaleta. 2012. The functions of biological diversity in an age of extinction. Science 336:14011406.

Needham, H. R., C. A. Pilditch, A. M. Lohrer, and S. F. Thrush. 2011. Habitat dependence in the functional traits of Austrohelice crassa, a key bioturbating species. Marine Ecology Progress Series 414:179-193.

Nielsen, L. P. 1992. Denitrification in sediment determined from nitrogen isotope pairing. FEMS Microbiology Letters $86: 357-362$. 
Norkko, A., and E. Bonsdorff. 1996a. Rapid zoobenthic community responses to accumulations of drifting algae. Marine Ecology Progress Series 131:143-157.

Norkko, A., and E. Bonsdorff. 1996b. Altered benthic preyavailability due to episodic oxygen deficiency cause by drifting algal mats. Marine Ecology 17:355-372.

Norkko, A., J. E. Hewitt, S. F. Thrush, and G. A. Funnell. 2006. Conditional outcomes of facilitation by a habitatmodifying subtidal bivalve. Ecology 87:226-234.

Norkko, J., A. Norkko, S. F. Thrush, S. Valanko, and H. Suurkuukka. 2010. Conditional responses to increasing scales of disturbance, and potential implications for threshold dynamics in soft-sediment communities. Marine Ecology Progress Series 413:253-266.

Scheffer, M., S. Carpenter, J. A. Foley, C. Folke, and B. Walker. 2001. Catastrophic shifts in ecosystems. Nature 413: 591-596.

Smith, M. D., A. K. Knapp, and S. L. Collins. 2009. A framework for assessing ecosystem dynamics in response to chronic resource alterations induced by global change. Ecology 90:3279-3289.

Solan, M., B. J. Cardinale, A. L. Downing, K. A. M. Engelhardt, J. L. Ruesink, and D. S. Srivastava. 2004. Extinction and ecosystem function in the marine benthos. Science 306:1177-1180.

Sousa, W. P. 1979. Disturbance in marine intertidal boulder fields: the nonequilibrium maintenance of species diversity. Ecology 60:1225-1239.

Sousa, W. P. 2001. Natural disturbance and the dynamics of marine benthic communities. Pages $85-130$ in M. D. Bertness, S. D. Gaines, and M. E. Hay, editors. Marine community ecology. Sinauer, Sunderland, Massachusetts, USA.

Srivastava, D. S., and M. Vellend. 2005. Biodiversity-ecosystem function research: is it relevant to conservation? Annual Review of Ecology, Evolution and Systematics 36:267-294.

Stanley, D. W., and S. W. Nixon. 1992. Stratification and bottom-water hypoxia in the Pamlico River estuary. Estuaries 15:270-281.

Statsoft. 2003. Statistica (data analysis software system). Statsoft, Tulsa, Oklahoma, USA.

Suding, K. N., and R. J. Hobbs. 2009. Threshold models in restoration and conservation: a developing framework. Trends in Ecology and Evolution 5:271-279.

Thrush, S. F., J. E. Hewitt, P. K. Dayton, G. Coco, A. M. Lohrer, A. Norkko, J. Norkko, and M. Chiantore. 2009. Forecasting the limits of resilience: integrating empirical research with theory. Proceedings of the Royal Society B 276: 3209-3217.

Thrush, S. F., J. E. Hewitt, and A. M. Lohrer. 2012. Interaction networks in coastal soft-sediments highlight the potential for change in ecological resilience. Ecological Applications 22: $1213-1223$.

Townsend, M., S. F. Thrush, and M. J. Carbines. 2011. Simplifying the complex: an 'Ecosystem Principles Approach' to goods and services management in marine coastal ecosystems. Marine Ecology Progress Series 434:291-301.

Tylianakis, J. M., T. A. Rand, A. Kahmen, A.-M. Klein, N. Buchmann, J. Perner, and T. Tscharntke. 2008. Resource heterogeneity moderates the biodiversity-function relationship in real world ecosystems. PLoS Biology 6:947-956.

Ulloa, O., D. E. Canfield, E. F. DeLong, R. M. Letelier, and F. J. Stewart. 2012. Microbial oceanography of anoxic oxygen minimum zones. Proceedings of the National Academy of Sciences USA. http://dx.doi.org/10.1073/pnas. 1205009109

Vahteri, P., A. Mäkinen, S. Salovius, and I. Vuorinen. 2000. Are drifting algal mats conquering the bottom of the Archipelago Sea, SW Finland? Ambio 29:338-343.

Vaquer-Sunyer, R., and C. M. Duarte. 2008. Thresholds of hypoxia for marine biodiversity. Proceedings of the National Academy of Sciences USA 105:15452-15457.

Veuger, B., and D. Van Oevelen. 2011. Long-term pigment dynamics and diatom survival in dark sediment. Limnology and Oceanography 56:1065-1074.

Villnäs, A., and A. Norkko. 2011. Benthic diversity gradients and shifting baselines: implications for assessing environmental status. Ecological Applications 21:2172-2186.

Villnäs, A., J. Norkko, K. Lukkari, J. Hewitt, and A. Norkko. 2012. Consequences of increasing hypoxic disturbance on benthic communities and ecosystem functioning. PLoS One $7: 1-12$.

Violle, C., M.-L. Navas, D. Vile, E. Kazakou, C. Fortunel, I. Hummel, and E. Garnier. 2007. Let the concept of trait be functional! Oikos 116:882-892.

Vitousek, P. M., H. A. Mooney, J. Lubchenco, and J. M. Melillo. 1997. Human domination of earth's ecosystems. Science 277:494-499.

White, P. S., and S. T. A. Pickett. 1985. Natural disturbance and patch dynamics: an introduction. Pages 3-13 in S. T. A. Pickett and P. S. White, editors. The ecology of natural disturbance and patch dynamics. Academic, Orlando, Florida, USA.

\section{Supplemental Material}

\section{Appendix A}

Schematic presentation of the hypoxic disturbance (Ecological Archives E094-210-A1).

\section{Appendix B}

Description of sediment properties at the experiment site (Ecological Archives E094-210-A2).

Appendix C

Disturbance-induced differences in ecosystem functions (Ecological Archives E094-210-A3).

Appendix D

Disturbance-induced changes in the macrofaunal community (Ecological Archives E094-210-A4). 